\title{
Pengaruh Karakteristik Psikografi terhadap Prestasi Kerja Anak Kandang pada Perusahaan Peternakan Ayam Broiler Skala Menengah di Kecamatan Tempel
}

\author{
S. Andarwati, T. Haryadi, dan L. E. Noviani \\ Fakultas Peternakan UGM, Jl. Fauna 3 Kampus UGM, Bulaksumur Yogyakarta 55281
}

\begin{abstract}
ABSTRAK
Penelitian ini bertujuan untuk mengetahui pengaruh karakteristik psikografi terhadap prestasi kerja anak kandang pada perusahaan peternakan ayam broiler skala menengah di Kecamatan Tempel. Penentuan responden menggunakan metode purposive sampling. Jumlah responden 30 anak kandang di perusahaan ayam broiler skala menengah dengan lama bekerja minimal 1 tahun. Pengukuran karakteristik psikografi yang terdiri dari motivasi berprestasi, persepsi status pekerjaan dan persepsi upah menggunakan skala Likert. Prestasi kerja anak kandang terdiri dari rasio konversi pakan dan persentase kematian ayam yang dipelihara oleh anak kandang. Analisis pengaruh antara karakteristik psikografi dengan prestasi kerja menggunakan analisis regresi binomial logistik. Hasil penelitian menunjukkan bahwa anak kandang memiliki motivasi berprestasi tinggi sebesar 66,67\%, motivasi sedang 30\% dan motivasi rendah sebesar 3,33\%. Persepsi anak kandang terhadap status pekerjaan memiliki nilai persepsi seimbang, yaitu tinggi 50\% dan rendah 50\%. Anak kandang juga memiliki persepsi terhadap upah yang adil yaitu $64 \%$ dan yang tidak adil $36 \%$. Prestasi kerja anak kandang hasilnya $66,67 \%$ memiliki prestasi tinggi dan 33,33\% memiliki prestasi rendah. Terdapat pengaruh yang signifikan $(\mathrm{P}<0,05)$ antara karakteristik psikografi dengan prestasi kerja anak kandang. Kesimpulan dari penelitian ini adalah karakteristik psikografi yang terdiri dari motivasi berprestasi, persepsi status pekerjaan dan persepsi upah yang tinggi berpengaruh terhadap kecenderungan prestasi kerja tinggi anak kandang.
\end{abstract}

Kata kunci: anak kandang, ayam broiler, prestasi kerja, karakteristik psikografi

\section{The Psychographic Characteristics Effect of Poultrymen's Job Achievement on Medium Scale Broiler Farm in Tempel District}

\begin{abstract}
This study aimed to determine the effect of psychographic characteristics toward the job achievment of poultrymen at medium scale broiler company in the Tempel District. The respondent was determined by judgement method. The number respondents were about 30 poultrymen whose at least 1 year experience to work. The measurement of psychographic characteristics consists motivation to achieve, perseption of work level and perception of salary based on Likert scale. The achievement of poultrymen were measured by the feed convertion ratio and the mortality of broilers kept by poultrymen. The analysis of psychographic characteristics influence toward job achievement was binomial logistic regression analysis. The results showed that poultrymen had high achievement motivation at $66.67 \%$, middle motivation $30 \%$, low motivation $3.33 \%$. The poultrymen perception about job status, that were about 50\% for high and $50 \%$ for low level. They also had perception about fair wages that is about $64 \%$ and 36 for unfair wages. The poultrymen job achievement were about $66.67 \%$ for high level and $33.33 \%$ for low level. There was significantly $(P \leq 0,05)$ between psychographic characteristics with the job achievement of poultrymen. The conclusion of this research were the higher psychographic characteristics these consist of motivation to achieve, perception of work level and perception of salary tended to have of high achievement of poultrymen.
\end{abstract}

Keyword: poultrymen, broiler, job achievement, psychographic characteristics 


\section{PENDAHULUAN}

Sektor usaha peternakan ayam broiler merupakan usaha yang menjanjikan. Menurut Fadilah (2004), perkembangan ayam broiler komersial di Indonesia dimulai pada pertengahan dasawarsa 1970-an dan booming pada awal 1980-an. Laju perkembangan usaha tersebut sejalan dengan pertumbuhan populasi penduduk, pergeseran gaya hidup, tingkat pendidikan, perkembangan situasi ekonomi, politik dan keamanan.

Peternakan ayam broiler membutuhkan berbagai faktor produksi penting, antara lain day old chicken (DOC), pakan, air minum, kandang, sarana kesehatan dan sumber daya manusia. Sumber daya manusia merupakan salah satu faktor yang menentukan keberhasilan suatu usaha. Tenaga kerja dalam usaha peternakan terbagi dalam berbagai tanggung jawab yang berbeda. Pemegang kebijakan biasanya dipegang langsung oleh pimpinan peternakan yang bertugas mengambil kebijakan untuk kelangsungan hidup peternakan dan bertanggung jawab terhadap gerak roda perusahaan. Pimpinan peternakan ini bertanggung jawab kepada pemilik peternakan. Pelaksanaan pengelolaan tugas ini, pimpinan perusahaan dibantu oleh tenaga kerja teknis dan non teknis.

Tenaga kerja teknis melibatkan berbagai faktor produksi, makanan dan pencegahan penyakit yang pada intinya menghasilkan produksi yang sesuai dengan tujuan peternakan. Sementara tenaga kerja non-teknis meliputi faktor administrasi umum yang sifatnya mendukung unsur teknis.

Salah satu tenaga teknis yaitu anak kandang yang menangani kegiatan proses produksi sehari-hari, serta kegiatan-kegiatan penunjang lainnya. Jenis pekerjaan yang dilakukan oleh anak kandang adalah memberi pakan, air minum, melakukan sanitasi dan vaksinasi serta panen produksi (Hardjono dan Maspiyati,1989).

Anak kandang menjadi penting karena mereka yang setiap hari berhubungan dengan ternak. Prestasi kerja yang dihasilkan anak kandang yang berupa feed convertion ratio (FCR) dan persentase kematian berkaitan dengan keuntungan perusahaan. Pencapaian tujuan perusahaan menjadi kurang efektif apabila banyak anak kandang yang tidak berprestasi dan hal ini akan menimbulkan pemborosan bagi perusahaan.

Selama ini, terdapat masalah dalam perusahaan karena tidak jelasnya aturan main di peternakan tersebut. Pekerja hanya memperoleh kewajiban saja tanpa memperoleh hak yang jelas. Ketidakjelasan tersebut akan berdampak atas kondisi dalam diri anak kandang. Selama ini asumsi yang ada adalah prestasi anak kandang hanya dipengaruhi oleh upah saja, namun ternyata ada hal lain yaitu karakteristik psikografi yang perlu dianalisis.

Karakteristik psikografi yang meliputi motivasi dan persepsi status pekerjaan serta persepsi upah, merupakan faktor yang berasal dari dalam individu anak kandang. Diharapkan dengan adanya motivasi berprestasi yang tinggi, persepsi status pekerjaan yang tinggi dan persepsi upah yang adil akan meningkatkan prestasi kerja anak kandang. Berdasarkan atas uraian tersebut, maka perlu diteliti pengaruh karakteristik psikografi yang berpengaruh terhadap prestasi kerja anak kandang.

\section{MATERI DAN METODE}

\section{Materi}

Materi dalam penelitian ini adalah 30 tenaga kerja (anak kandang) ayam broiler skala menengah di Kecamatan Tempel, Sleman, Yogyakarta. Alat bantu pengumpulan data adalah kuesioner yang telah diuji validitas dan reliabilitasnya.

\section{Metode}

Penelitian dilakukan dengan metode survai, melalui dua tahap kegiatan, yaitu prasurvai dan survai. Tahap pra-survai dilakukan untuk menentukan lokasi dan sampel peternak. Tahap survai dilakukan untuk mendapatkan data yang dicari dalam penelitian. 


\section{Sampel daerah}

Sampel kecamatan dipilih secara purpossive sampling atau sengaja dengan pertimbangan bahwa Kecamatan Tempel merupakan daerah dengan jumlah pengusaha ayam broiler terbesar di Sleman. Soeratno dan Arsyad (1999), menyatakan purpossive sampling adalah mengambil sampel berdasarkan penilaian atau pertimbangan dari peneliti, yaitu menurut ciri-ciri khusus yang dimiliki oleh sampel sehingga relevan dengan rancangan penelitian. Penelitian ini dilakukan di Desa Sumberejo dan Pondokrejo kecamatan Tempel. Data dari Profil Peternakan Tahun 2010 Kabupaten Sleman menyatakan kedua desa tersebut memiliki jumlah peternak dan populasi ayam broiler skala menengah terbanyak di Kecamatan Tempel (Anonim, 2010).

\section{Sampel responden}

Responden diambil secara purpossive sampling sebanyak 30 tenaga kerja (anak kandang) pada peternakan ayam broiler skala menengah yang telah bekerja minimum 1 tahun di Desa Sumberrejo dan Pondokrejo Kecamatan Tempel.

\section{Sumber data}

Data yang dikumpulkan dalam penelitian ini adalah : (1) data primer diperoleh melalui wawancara dengan anak kandang, instrumen yang digunakan adalah kuesioner, dan (2) data sekunder yang diperoleh dari literatur-literatur dan informasi dinas terkait yang berhubungan dengan sistem upah dan peternakan ayam broiler.

Data primer terdiri dari a) identitas responden b) karakteristik psikografi yang meliputi motivasi dan persepsi c) prestasi kerja yang meliputi feed convertion ratio (FCR) dan persentase kematian. Data sekunder terdiri dari data perusahaan peternakan ayam broiler di Kecamatan Tempel Kabupaten Sleman.

\section{Pengujian instrumen}

Pengujian validitas dan reliabilitas dilaksanakan di desa Girikerto yang memiliki populasi ayam skala menengah terbanyak di Kecamatan Turi. Kecamatan Turi merupakan daerah yang berbatasan langsung dengan Kecamatan Tempel, sehingga karakteristiknya mirip dengan Kecamatan Tempel. Dalam penelitian ini responden diambil secara purpossive sampling sebanyak 30 tenaga kerja (anak kandang) pada peternakan ayam broiler skala menengah yang telah bekerja minimum 1 tahun.

\section{Analisis Data}

Pengaruh karakteristik psikografi terhadap prestasi kerja dianalisis menggunakan analisis regresi binomial logistik. Analisis regresi binomial logistik digunakan untuk mengetahui faktor-faktor yang berpengaruh terhadap prestasi kerja. Analisis regresi binomial logistik adalah analisis regresi yang memiliki dua nilai didalamnya. Alasan digunakannya analisis regresi binomial logistik yaitu: 1) dalam penelitian ini hanya dibedakan dua nilai yaitu prestasi kerja tinggi dan prestasi kerja rendah, 2) variabel terikat (dependent variable) dalam penilaian ini bersifat kualitatif (Santoso dan Azhari, 2005). Analisis regresi logistik biner digunakan untuk melihat pengaruh sejumlah variabel independen $x_{1}, x_{2}, \ldots, x_{k}$ terhadap variabel dependen $y$ yang berupa variabel response biner yang hanya mempunyai dua nilai atau juga untuk memprediksi nilai suatu variabel dependen $y$ (yang berupa variabel biner) berdasarkan nilai variabel - variabel independen $x_{1}, x_{2}, \ldots, x_{k}$ (Uyanto, 2009). Analisis regresi binomial logistik sebagai berikut:

$$
\begin{aligned}
& \log \left[\frac{\operatorname{prob}(\text { event })}{\operatorname{prob}(\text { no event })}\right] \\
& =\beta_{0}+\beta_{1} X_{1}+\beta_{2} X_{2}+\ldots+\beta_{k} X_{k}
\end{aligned}
$$

Keterangan:

$\beta_{0}-\beta_{k}=$ Koefisien regresi

$\mathrm{X}_{1}-\mathrm{X}_{\mathrm{K}}=$ Variabel independen (total skor)

(Norusis cit. Haryadi, 2002) 
Selanjutnya rumus umum analisis regresi binomial logistik tersebut diterapkan dalam penelitian menjadi:

$\log \left[\frac{\text { prob(prestasitinggi) }}{\text { prob(prestasirendah })}\right]$

$=\beta_{0}+\beta_{1} X_{1}+\beta_{2} X_{2}+\beta_{3} X_{3}$

Keterangan:

$\beta_{0}-\beta_{k}=$ Koefisien regresi

$X_{1} \quad=$ Motivasi berprestasi (total skor)

$X_{2} \quad=$ Persepsi status pekerjaan (total skor)

$X_{3} \quad=$ Persepsi upah (total skor)

\section{Analisis motivasi}

David McClelland (Munandar, 2006) dalam teorinya McClelland's Achievement Motivation Theory atau Teori Motivasi Berprestasi McClelland yang dikemukakan pada tahun 1961, mengemukakan bahwa individu mempunyai cadangan energi potensial, bagaimana energi ini dilepaskan dan dikembangkan tergantung pada kekuatan atau dorongan motivasi individu dan situasi serta peluang yang tersedia. Teori ini memfokuskan pada tiga kebutuhan yaitu kebutuhan akan prestasi (need for achievement), kebutuhan kekuasaan (need for power), dan kebutuhan afiliasi (need for affiliation). Model motivasi ini ditemukan diberbagai lini organisasi, baik staf maupun manajer. Beberapa karyawan memiliki karakter yang merupakan perpaduan dari model motivasi tersebut. Teori Motivasi Berprestasi McClelland tersebut yang digunakan untuk mendukung analisis yang akan dikemukakan dalam penelitian ini.

Perhitungan tiga kebutuhan dalam analisis motivasi dibuat dengan pernyataanpernyataan dalam bentuk kuesioner. Kuesioner terdiri dari 21 pertanyaan motivasi, dengan 9 pertanyaan motivasi berprestasi, 7 pertanyaan motivasi berkuasa dan 5 pertanyaan motivasi berafiliasi. Tahapan perhitungan motivasi dengan : 1) menentukan skor alternatif jawaban dengan metode Likert (skor 1 untuk jawaban sangat tidak setuju, skor 2 untuk jawaban tidak setuju, skor 3 untuk jawaban ragu-ragu, skor 4 untuk jawaban setuju, dan skor 5 untuk jawaban sangat setuju), untuk pernyataan negatif, skor jawaban adalah kebalikan dari pertanyaan positif, 2) skor jawaban untuk masing-masing jenis kebutuhan dijumlahkan, dan 3) menentukan skor maksimum dan minimum, dengan rumus:

Skor maksimum : (skor tertinggi $\mathrm{x}$ jumlah pernyataan)

Skor minimum : (skor terendah $\mathrm{x}$ jumlah pertanyaan)

dan 4) kategori kebutuhan dapat diketahui berdasar kisaran skor maksimum dan skor minimum dibagi menjadi tiga tingkatan kategori motivasi yaitu tinggi, sedang dan rendah. Batas interval kategori diperoleh melalui rumus sebagai berikut :

Interval kategori:

$\left[\frac{\text { Nilai maksimal - nilai minimal }}{\text { jumlah kategori }}\right]$

(Azwar, 2002)

Pengukuran ini dapat menghasilkan skor motivasi sebesar 21 x $5=105$ yang mencerminkan motivasi tinggi, dan skor motivasi rendah adalah 21 x $1=21$. Berdasarkan nilai batas maksimal dan minimal prestasi serta dibagi dalam 3 kategori, maka diperoleh skor jawaban 21 sampai dengan nilai 49 diklasifikasikan motivasi rendah, >49 sampai 77 diklasifikasikan motivasi sedang dan perolehan skor jawaban $>77$ sampai dengan 105 diklasifikasikan motivasi tinggi (Tabel $1)$.

Tabel 1. Kriteria kategori variabel motivasi berprestasi anak kandang

\begin{tabular}{lc}
\hline \hline Kategori & Skor \\
\hline Rendah & $21-49$ \\
Sedang & $>49-77$ \\
Tinggi & $>77-105$ \\
\hline
\end{tabular}

Sumber : Data primer terolah (2013)

\section{Analisis persepsi status pekerjaan dan persepsi upah}

Skala persepsi diukur dengan menggunakan skala Likert. Menurut Supranto (1997), skala Likert merupakan salah satu pengukuran yang sering digunakan untuk mengukur atribut-atribut 
objek penelitian yang bersifat kualitatif. Skala ini terdiri dari 5 kategori, yaitu: sangat setuju (skor 5), setuju (skor 4), ragu-ragu (skor 3), tidak setuju (skor 2), dan sangat tidak setuju (skor 1).

Item-item persepsi terhadap upah berdasarkan aspek keadilan dalam pemberian upah yang dikemukakan oleh Simamora (1999), yaitu : 1) keadilan eksternal, 2) keadilan internal, dan 3) keadilan individu, untuk persepsi status pekerjaan berdasarkan penilaian responden terhadap status pekerjaannya sebagai anak kandang.

Skor jawaban dari setiap pernyataan dijumlahkan, kemudian dicari skor maksimum dan skor minimum. Berdasarkan skor maksimum dan skor minimum pada persepsi terhadap upah dilakukan pengkategorian dengan menentukan batas interval kategori. Batas interval kategori diperoleh melalui rumus sebagai berikut :

Interval kategori:

$\left[\frac{\text { Nilai maksimal - nilai minimal }}{\text { jumlah kategori }}\right]$

\section{( Azwar, 2002 )}

Berdasarkan rumus interval, maka kategori persepsi status pekerjaan dan upah dibagi menjadi dua kategori, yaitu kategori tinggi dan kategori rendah untuk persepsi status pekerjaan, dan kategori adil dan tidak adil untuk persepsi upah.

Nilai maksimal untuk persepsi status pekerjaan adalah 7 x $5=35$ dan nilai minimal untuk persepsi status pekerjaan adalah $7 \times 1=7$. Berdasarkan rumus interval kategori, maka distribusi interval 7 sampai 21 merupakan kategori persepsi rendah, dan interval 22 sampai 35 merupakan interval persepsi tinggi (Tabel 2).

Tabel 2. Kriteria kategori variabel persepsi status pekerjaan

\begin{tabular}{lr}
\hline Kategori & Skor \\
\hline Tinggi & $22-35$ \\
Rendah & $7-21$ \\
\hline
\end{tabular}

Sumber : Data primer terolah (2013)
Persepsi terhadap upah, kategorinya dibagi menjadi persepsi upah adil dan persepsi upah tidak adil. Nilai maksimal untuk persepsi upah adil adalah $6 \times 5=30$ dan nilai minimal untuk persepsi upah tidak adil adalah $6 \times 1=6$. Berdasarkan rumus interval kategori, maka distribusi interval 6 sampai 18 merupakan kategori persepsi tidak adil, dan interval 19 sampai 30 merupakan persepsi upah adil (Tabel 3). Makin tinggi skor yang diperoleh responden berarti semakin adil persepsi terhadap pekerjaan dan persepsi terhadap upah, demikian juga sebaliknya semakin rendah skor yang diperoleh responden berarti semakin tidak adil persepsi terhadap pekerjaan dan upah.

Tabel 3. Kriteria kategori variabel persepsi upah

\begin{tabular}{lc}
\hline \hline Kategori & Skor \\
\hline Adil & $19-30$ \\
Tidak adil & $6-18$ \\
\hline
\end{tabular}

Sumber : Data primer terolah (2013)

\section{HASIL DAN PEMBAHASAN}

\section{Karakteristik Responden}

Responden dalam penelitian ini berjumlah 30 orang. Responden merupakan anak kandang pada peternakan ayam broiler di Desa Pondokrejo dan Sumberrejo. Anak kandang yang dijadikan responden pada saat penelitian adalah anak kandang yang telah bekerja selama 1 tahun dalam perusahaan ayam broiler dengan kapasitas usaha 3000 sampai 8000 ayam broiler. Karakteristik responden dalam penelitian ini meliputi jenis kelamin, umur, tingkat pendidikan, dan lama bekerja. Uraian karakteristik responden lebih lanjut tersaji pada Tabel 4.

Rata-rata jenis kelamin responden adalah 93,33\% laki-laki, hal ini menunjukkan bahwa bidang usaha peternakan ayam broiler masih didominasi oleh tenaga kerja atau anak kandang lakilaki. Kondisi ini dimungkinkan karena pekerjaan anak kandang dipandang sebagai pekerjaan yang membutuhkan banyak 
Tabel 4. Karakteristik responden

\begin{tabular}{|c|c|}
\hline Karakteristik Responden & Nilai \\
\hline \multicolumn{2}{|l|}{ Jenis kelamin $(\%)$} \\
\hline - laki-laki & 93,33 \\
\hline - perempuan & 6,67 \\
\hline Rata-rata umur (tahun) & $32,73 \pm$ \\
\hline Rata-rata pendidikan & 9,54 \\
\hline (tahun) & $10,4 \pm 1,8$ \\
\hline \multicolumn{2}{|l|}{ Pendidikan $(\%)$} \\
\hline$-\mathrm{SD}$ & 6,67 \\
\hline - SMP & 40 \\
\hline - SMA & 53,33 \\
\hline $\begin{array}{l}\text { Rata-rata lama bekerja } \\
\text { (tahun) }\end{array}$ & $7 \pm 4,62$ \\
\hline
\end{tabular}

Sumber : Data primer terolah (2013)

Tabel 5. Distribusi kategori motivasi berprestasi

\begin{tabular}{lccc}
\hline \hline \multicolumn{1}{c}{ Indikator Motivasi } & \multicolumn{3}{c}{ Kategori $(\%)$} \\
\cline { 2 - 4 } & Tinggi & Sedang & Rendah \\
\hline Kebutuhan berprestasi & 63,33 & 33,33 & 3,33 \\
Kebutuhan berkuasa & 90,00 & 3,33 & 6,67 \\
Kebutuhan berafiliasi & 63,33 & 33,33 & 3,33 \\
\hline Motivasi berprestasi & 66,67 & 30 & 3,33 \\
\hline
\end{tabular}

Sumber: Data primer terolah (2013)

Tabel 6. Distribusi kategori persepsi status pekerjaan

\begin{tabular}{lc}
\hline \hline Kategori & Persentase(\%) \\
\hline Tinggi & 50 \\
Rendah & 50 \\
\hline
\end{tabular}

Sumber: Data primer diolah (2013)

curahan tenaga secara fisik dan lebih cocok jika yang bekerja adalah laki-laki.

Kisaran umur responden adalah 20 sampai 53 tahun (rata-rata 32,73 \pm 9,54). Kisaran umur tersebut menunjukkan bahwa anak kandang merupakan usia produktif. Badan Pusat Statistik menyatakan kategori usia produktif 15 sampai 65 tahun (Rusli, 1996).

Tingkat pendidikan sejalan dengan tingkat produktivitas dan efisiensi kerja. Semakin tinggi kompleksitas pekerjaan, membutuhkan pendidikan yang lebih tinggi pula (Djamali, 2000). Lama pendidikan yang ditempuh anak kandang merupakan faktor yang erat kaitannya dengan kemampuan anak kandang dalam menyelesaikan pekerjaannya. Rata-rata lama pendidikan yang ditempuh anak kandang adalah 10,4 \pm 1,8 tahun, dengan yang menempuh pendidikan SD sebanyak 2 orang $(6,67 \%)$, sedangkan yang menempuh pendidikan formal selama 6 sampai 9 tahun atau setara dengan SMP sebanyak 12 orang (40\%) dan jumlah responden yang menempuh pendidikan selama 9 sampai 12 tahun atau setara dengan tingkat SMA sebanyak 16 orang $(53,33 \%)$. Berdasarkan data tersebut, rata-rata pendidikan anak kandang adalah setingkat SMA.

Kisaran lama bekerja adalah 1 sampai 20 tahun dengan rata-rata lama 
bekerja responden yaitu $7 \pm 4,62$ tahun. Semakin lama seseorang bekerja pada suatu organisasi maka komitmennya terhadap organisasi juga semakin baik dan produktivitas perusahaan meningkat (Putri, 2011).

\section{Karakteristik Psikografi Anak Kandang}

Anak kandang sebagai pelaksana dalam pemeliharaan ayam, merupakan faktor penentu dalam mencapai keberhasilan usaha peternakan ayam broiler. Ada beberapa karakteristik psikografi yang diduga mempengaruhi prestasi kerja anak kandang, yaitu motivasi berprestasi, persepsi status pekerjaan dan persepsi upah.

\section{Motivasi berprestasi}

Motivasi berprestasi anak kandang terlihat bahwa $66,67 \%$ anak kandang memiliki motivasi tinggi untuk berprestasi, $30 \%$ memiliki motivasi sedang, dan 3,33\% memiliki motivasi rendah dalam berprestasi (Tabel 5). Hal ini menunjukkan bahwa anak kandang memiliki keinginan yang besar untuk berprestasi dalam bekerja.

\section{Persepsi status pekerjaan}

Persepsi anak kandang terhadap status pekerjaannya ditunjukkan pada Tabel 6, yaitu 50\% berpersepsi tinggi dan 50\% berpersepsi rendah atas status pekerjaannya sebagai anak kandang. Kondisi ini menggambarkan bahwa belum semua anak kandang memiliki persepsi yang baik terhadap status pekerjaan sebagai anak kandang yang digelutinya saat ini.

\section{Persepsi upah}

Persepsi anak kandang atas persepsi upah sebesar $64 \%$ memiliki persepsi adil dan $36 \%$ memiliki persepsi tidak adil atas upah yang diterimanya (Tabel 7). Hal ini menunjukkan bahwa upah yang diterima anak kandang sudah cukup, sehingga mayoritas mempersepsikan adil.

\section{Prestasi Kerja Anak Kandang}

Prestasi kerja anak kandang memiliki dua indikator yaitu feed convertion ratio
(FCR) dan persentase kematian (\%) ayam broiler yang menjadi tanggungjawab anak kandang. Hasil perhitungan FCR dan persentase kematian ayam broiler ditunjukkan pada Tabel 8. Rata-rata anak kandang memiliki prestasi kerja berupa feed convertion ratio $(\mathrm{FCR})$ ayam sebesar 1,63 \pm 0,16 dengan nilai minimal FCR 1,02 dan nilai maksimal FCR 1,9. Rata-rata nilai FCR ayam yang dipelihara anak kandang lebih rendah dibandingkan dengan rata-rata standar FCR perusahaan yaitu sebesar 1,70 \pm 0,07 (Tabel 9). Hal ini menunjukkan bahwa FCR ayam broiler yang dipelihara anak kandang lebih kecil dari standar yang ditetapkan perusahaan sehingga prestasi anak kandang dianggap baik.

Tabel 7. Distribusi kategori persepsi upah

\begin{tabular}{lc}
\hline \multicolumn{1}{c}{ Kategori } & Persentase $(\%)$ \\
\hline Adil & 64 \\
Tidak adil & 36 \\
\hline
\end{tabular}

Sumber: Data primer terolah (2013).

Tabel 8. Rata-rata prestasi kerja anak kandang

\begin{tabular}{lc}
\hline \hline \multicolumn{1}{c}{ Rata-Rata Prestasi Kerja } & Nilai \\
\hline Feed convertion ratio & $1,63 \pm 0,16$ \\
Persentase kematian $(\%)$ & $4,02 \pm 1,04$ \\
\hline
\end{tabular}

Sumber: Data primer terolah (2013)

Rata-rata prestasi anak kandang berupa persentase kematian ayam broiler sebesar 4,02 $\pm 1,04$ (Tabel 8) dengan nilai minimal sebesar $2 \%$ dan maksimal $6 \%$ kematian ayam broiler dalam satu periode. Rata-rata standar persentase kematian ayam jika dibandingkan dengan persentase kematian ayam yang diterapkan perusahaan, yaitu sebesar 4,88 $\pm 0,71$ (Tabel 9) maka nilai kematian ayam yang dipelihara anak kandang dianggap baik karena nilai kematian ayam lebih rendah dari standar. Standar rata-rata prestasi kerja yang ditetapkan perusahaan dapat diamati pada Tabel 9.

Prestasi kerja anak kandang secara keseluruhan juga tergolong tinggi (Tabel 10), hal ini terlihat dari kategori prestasi anak kandang yang tinggi sebesar $66,67 \%$ 
Tabel 9. Standar rata-rata prestasi kerja yang ditetapkan perusahaan

\begin{tabular}{lc}
\hline \multicolumn{1}{c}{ Prestasi Kerja } & Nilai \\
\hline Feed Convertion Ratio & $1,70 \pm 0,07$ \\
Persentase kematian $(\%)$ & $4,88 \pm 0,71$ \\
\hline
\end{tabular}

Sumber: Data primer terolah (2013).

Tabel 10. Kategori prestasi kerja anak kandang

\begin{tabular}{lcc}
\hline \hline & Prestasi Kerja & Nilai (\%) \\
\hline Tinggi & 66,67 \\
Rendah & 33,33 \\
\hline
\end{tabular}

Sumber: Data primer terolah (2013)

Tabel 11. Hasil analisis regresi binomial logistik karakteristik psikografi anak kandang terhadap prestasi kerja

\begin{tabular}{lrcc}
\hline \multicolumn{1}{c}{ Variabel Bebas } & $\beta$ & Probability & Exponential $\beta$ \\
\hline Motivasi berprestasi $\left(\mathrm{X}_{1}\right)$ &, 097 &, $034^{*}$ & 1,102 \\
Persepsi status pekerjaan $\left(\mathrm{X}_{2}\right)$ &, 212 &, $048^{*}$ & 1,237 \\
Persepsi upah $\left(\mathrm{X}_{3}\right)$ &, 237 &, $047^{*}$ & 1,267 \\
Constant & $-16,748$ &, $015^{*}$ &, 000 \\
\hline
\end{tabular}

Correct prediction 90\%, Chi square 21,269 (P $\leq 0,01)$, Keterangan : *P $\leq 0,05$

Sumber : Data primer terolah (2013).

dan prestasi kerja anak kandang yang rendah sebesar $33,33 \%$.

\section{Pengaruh karakteristik psikografi terhadap prestasi kerja}

Hasil analisis regresi binomial logistik menunjukkan bahwa motivasi berprestasi, persepsi status pekerjaan dan persepsi upah berpengaruh signifikan $(\mathrm{P} \leq 0,05)$ terhadap prestasi kerja anak kandang (Tabel 11). Hal tersebut mengindikasikan semakin tinggi motivasi berprestasi, persepsi status pekerjaan dan persepsi upah, maka anak kandang cenderung untuk memiliki prestasi kerja yang tinggi. Nilai chi square memiliki nilai $21,269(\mathrm{P} \leq 0,01)$, sehingga model sangat layak digunakan.

$$
\text { Variabel-variabel independen }
$$

(motivasi berprestasi, persepsi status pekerjaan dan persepsi upah) secara serentak berpengaruh terhadap variabel dependennya yaitu prestasi kerja.
Tabel 11 menunjukkan bahwa correct prediction sebesar 90\%, artinya bahwa faktor karakteristik psikografi yang meliputi motivasi berprestasi, persepsi status upah dan persepsi pekerjaan terbukti mempengaruhi kecenderungan prestasi tinggi atau prestasi rendah anak kandang dengan prediksi kebenaran 90\%. Persamaan regresi binomial logistiknya sebagai berikut:

$$
\begin{aligned}
& \log \left[\frac{\text { prob }(\text { prestasitinggi })}{\text { prob }(\text { prestasirendah })}\right] \\
& =-16,748+0,097 X_{1}+0,212 X_{2}+0,237 X_{3}
\end{aligned}
$$

Keterangan:

$X_{1}=$ Motivasi berprestasi (total skor)

$X_{2} \quad=$ Persepsi status pekerjaan (total skor)

$X_{3} \quad=$ Persepsi upah (total skor)

Hasil penelitian menunjukkan bahwa variabel motivasi berprestasi, persepsi status pekerjaan dan persepsi upah mempengaruhi 
kecenderungan prestasi kerja anak kandang. Hasil analisis diketahui arah koefisien logit untuk semua variabel bernilai positif, artinya semakin tinggi motivasi berprestasi, persepsi status pekerjaan dan persepsi upah maka anak kandang cenderung berprestasi tinggi.

Persepsi status pekerjaan dan persepsi upah jika dianggap konstan, maka anak kandang cenderung untuk berprestasi tinggi. Peluang prestasi tinggi anak kandang naik sebesar 1,102 kali untuk setiap kenaikan skor motivasi berprestasi.

Motivasi berprestasi dan persepsi upah jika dianggap konstan, maka anak kandang cenderung untuk berprestasi tinggi. Peluang prestasi tinggi anak kandang naik sebesar 1,237 kali untuk setiap kenaikan skor persepsi status pekerjaan. Motivasi berprestasi dan persepsi status pekerjaan jika dianggap konstan, maka anak kandang cenderung berprestasi tinggi. Peluang prestasi tinggi anak kandang naik sebesar 1,267 kali untuk setiap kenaikan skor persepsi upah.

Motivasi berprestasi, persepsi status pekerjaan dan status upah yang tinggi, dapat melandasi tingginya prestasi kerja anak kandang. Swastha (1989) menyatakan motivasi berprestasi dalam bekerja dapat mendorong semangat kerja, karena kuat lemahnya motivasi berprestasi seseorang ikut menentukan besar kecilnya prestasi kerja. Sarlito (1993) dalam Syaiin (2007) menyatakan beberapa hal yang menyebabkan perbedaan dalam persepsi antara lain perhatian, harapan seseorang akan rangsangan yang timbul, kebutuhan sistem nilai dan ciri kepribadiannya sehingga setiap orang mempunyai prestasi berbedabeda terhadap suatu rangsangan. Status pekerjaan yang dipersepsikan tinggi maka akan menimbulkan prestasi kerja yang tinggi. Sujatmoko (2007) menyatakan upah berpengaruh positif terhadap prestasi kerja.

\section{SIMPULAN}

Berdasarkan penelitian yang telah dilakukan, dapat disimpulkan bahwa motivasi berprestasi, persepsi status pekerjaan dan persepsi upah berpengaruh terhadap kecenderungan untuk berprestasi kerja tinggi atau rendah. Semakin tinggi motivasi berprestasi, persepsi status pekerjaan dan persepsi upah maka anak kandang akan memiliki kecenderungan untuk berprestasi tinggi dalam bekerja. Semakin rendah motivasi berprestasi, persepsi status pekerjaan dan persepsi upah maka anak kandang akan memiliki kecenderungan untuk berprestasi rendah dalam bekerja.

\section{DAFTAR PUSTAKA}

Anonim. 2010. Profil Peternakan Tahun 2010. Bidang Peternakan Dinas Pertanian dan Kehutanan Sleman. Yogyakarta.

Azwar, S. 2002. Sikap Manusia Teori dan Pengukurannya. Pustaka Pelajar. Yogyakarta.

Djamali, A. R. 2000. Manajemen Usahatani. Departemen Pendidikan Nasional Politeknik Pertanian Negeri Jember. Jurusan Manajemen Agribisnis. Jember.

Fadilah, R. 2004. Kunci Sukses Beternak Ayam Broiler di Daerah Tropis. Agromedia Pustaka. Jakarta.

Hardjono, J dan Maspiyati. 1989. Organisasi Produksi dan Ketenagakerjaan pada Industri Perunggasan di Jawa Barat. Institut Pertanian Bogor. Bogor.

Haryadi, F. T. 2002. Study on The Diffusion Process of Agricultural Technology Innovation. Science of Plant and Animal Production, Management and Economics of Agriculture and Forestry. United Graduate School of Agricultural Science, Tokyo University of Agriculture and Technology, Tokyo.

Munandar, A. S. 2006. Psikologi Industri dan Organisasi. UI-Press. Jakarta.

Putri, W.R. 2011. Pengaruh Komitmen Organisasi terhadap Kinerja Pegawai Negeri Sipil pada Badan Perpustakaan Arsip dan Dokumentasi (BPAD) Provinsi Sumatera Utara. Skripsi Sarjana Manajemen. Universitas Sumatera Utara. Medan.

Rusli, S. 1996. Pengantar Ilmu Kependudukan. Pustaka LP3ES. Jakarta. 
Santosa, P. B. dan Ashari. 2005. Analisis Statistik dengan Microsoft Excel dan SPSS. Penerbit ANDI. Yogyakarta.

Simamora, H. 1999. Manajemen Sumber Daya Manusia. Edisi kedua. STIE YKPN. Yogyakarta.

Soeratno dan Arsyad, L. 1999. Metodologi Penelitian untuk Ekonomi dan Bisnis. UPP AMP YKPN. Yogyakarta.

Sujatmoko, K. 2007. Pengaruh Insentif Terhadap Peningkatan Prestasi Kerja Karyawan pada Departemen Operasional Pemasaran di Dunkin' Donuts Cabang Arteri Jakarta. Skripsi Pascasarjana
Ekonomi. Universitas Sumatera Utara. Medan.

Supranto, J. M.A. 1997. Metode Riset, Aplikasinya Dalam Pemasaran. Edisi revisi. Rineka Cipta. Jakarta.

Swastha. 1989. Asas-Asas Marketing. Edisi ketiga. Liberty. Yogyakarta

Syaiin, B. 2007. Pengaruh Kepuasan Kerja terhadap Kinerja Pegawai Klinik Spesialis Bestari Medan. Sekolah Pasca Sarjana Kesehatan. Universitas Sumatera Utara. Medan.

Uyanto, S. 2009. Pedoman Analisis Data dengan SPSS. Edisi 3. Graha Ilmu, Yogyakarta. 